Pierre Gamache*

\title{
Last Copies Initiative: Permanent Conservation of Print Collection in Canada
}

https://doi.org/10.1515/bfp-2017-0039

\begin{abstract}
This article is a written version of the presentation "Last Copies Initiative: Permanent Conservation of Print Collections in Canada” made in November 2016 in Göttingen, Germany. This article describes the Canadian context that enabled this initiative, its success in the development of its framework, and the issues it faced in its implementation. It concludes on lessons learned and next steps.
\end{abstract}

Keywords: Last copies; shared print; print archives

\section{Die Last-Copy-Initiative: Eine nachhaltige Konservierung von gedruckten Sammlungen in Kanada}

Zusammenfassung: Dieser Beitrag ist die schriftliche Version des Vortrags „Die Last-Copy-Initiative: Eine nachhaltige Konservierung der gedruckten Sammlungen in Kanada“, der in Göttingen im November 2016 gehalten wurde. Der Beitrag beschreibt den kanadischen Kontext dieser Initiative, den Fortschritt in der Entwicklung der Struktur und die Herausforderungen, die sich bei der Implementierung zeigen. Er schließt mit der Beschreibung der bisherigen Erfahrungen und der nächsten Schritte.

Schlüsselwörter: Last Copy; gemeinsamer Druck; Druckarchiv

\section{Context}

The Canadian library community is diverse and includes a wide range of institutions with different mandates, e.g., academic, public, special libraries, and is also composed of institutions of various sizes. This community has a rich tradition of resource sharing, including consortia effort to rationalize management of collection, and to prevent disposal of last copies. This effort which is not limited to existing consortia but is present at the institutional level, is directly linked to a goal of reducing redundancies across collections, especially if digital versions of the corresponding content are widely available. Also, it is often related to goals of decreasing the use of physical space, which in

*Kontaktperson: Pierre Gamache, pierre.gamache102@gmail.com turn may be linked to digitization projects. However, the library community has also recognized the risk that in the process, all copies of a given item may be disposed of, thus leaving no Canadian holdings available. The particularities of Canadian geography and demographics, i.e. a rather small population in a large country with specific areas of population concentration, add an important element to this context, as copies must remain available to institutions and public within a reasonable distance.

In this context, a number of regional initiatives have been undertaken, and among them some have had a panCanadian influence. In a 2011 report the Council of Prairie and Pacific University Libraries (COPPUL) proposed "a business model, organizational model, and a memorandum of understanding to support a distributed regional print archiving program [...] designed to create significant opportunities for space reclamation while preserving scholarly record in the region". ${ }^{1}$ Twenty COPPUL libraries have joined this initiative. In 2008 the Ontario Council of University Libraries (OCUL) composed of 21 libraries in that province "agreed on a strategy to address the challenges of maintaining low-use and last copy materials [...] agreed to focus attention on the coordinated retention and collaborative storage of print journals". ${ }^{2}$ In turn the "Conférence des Recteurs et des Principaux des Universités du Québec (CREPUQ)"3 representing 18 university libraries endorsed resolutions along the same lines with a particular focus on journal titles.

At the national level the Canadian Association of Research Libraries (CARL) represents 29 large academic libraries in the country, as well as Federal institutions. In 2009 it established the Permanent Conservation of Print Collections Working Group to identify best practices for the management of print materials. In doing so, it held consultations with regional library consortia, i.e. COPPUL, OCUL, CREPUQ. The CARL working group issued a report in April 2011 that contained four general principles:

1 Stambaugh (2011) 3.

2 Ontario Council of University Libraries, Board of Directors meeting, April 30, 2009.

3 Note: Conference of Rectors and Principals of Quebec Universities. 
"That CARL libraries agree in principle to weed print items from their collections only after determining that a 'reasonable' number of copies exist in other CARL libraries (including our federal/ national members). The exact number of copies will have to be determined, and may vary by class of material. [...] That an appropriate database (e.g., Amicus, OCLC) serves as the source of evidence of the number of copies [...]. That CARL libraries each commit to regular uploading of their holdings records to a database such as Amicus or OCLC [...] that 'last copies' be marked as last or rare copies in some way". ${ }^{4}$

The role of Library and Archives Canada (LAC) in this environment cannot be discussed without its broader context. LAC was established in 2004, as the result of the merger of the National Library of Canada and the National Archives. It fulfills through its legislation the mandate of the former National Library for Canada that was originally founded in 1953. Its published collection comprises about 20 million items in a variety of formats: books, serials, newspapers, microforms, as well as electronic/digital formats. This collection is focused mostly on Canadiana: material published in Canada acquired through Legal Deposit since 1953, as well as material by Canadian creators published prior to Legal Deposit, and by Canadians or about Canada published outside the country. Its collection of non Canadiana material is much smaller, and is oriented towards providing reference services to the public, or on some specific themes. In essence, LAC is a fairly recent institution and is one of the many large libraries in the country.

\section{Actions taken}

In May 2011, LAC hosted a meeting of the Pan-Canadian Documentary Heritage Network (PCDHN) representing key constituents involved in the management of documentary heritage. The CARL report influenced strongly the discussions at this meeting. Following these initial discussions, an "Analogue Collaboration Group" of the PCDHN was formed and it agreed to tackle the issue. The members of this Group were representatives from COPPUL, CARL, the Canadian Historical Association (CHA), the Association of Parliamentary Libraries in Canada (APLIC), the University of British Columbia, University of Alberta, University of Manitoba, and the Library of Parliament. In early 2012 the group produced a set of 6 principles. Institutions will:

- Communicate their willingness to hold a last copy of documentary heritage

- Communicate to other participating institutions the documentary heritage they hold as last copy

4 Canadian Association of Research Libraries (2011).
- Undertake to hold last copies in an appropriate preservation environment

- Undertake to give reasonable access to last copies

- Agree not to dispose of a last copy without reasonable notice to other participating institutions

- Undertake, if proceeding to dispose of a last copy, to accommodate its transfer to another institution

More specifically: participating institutions will communicate their willingness to be a last copy repository through bilateral or multilateral discussions. They will designate from their current holdings the titles for which they are willing to accept responsibility to maintain and hold as last copies, and that will be identified as such, most likely in the National Union Catalogue. They will commit to store them in facilities with adequate climate control and security, and to provide reasonable protection for last copies against damage or loss. They will agree to allow reasonable access for Canadians to last copies, with the understanding that depending on institutional policies access may be digital, on-site, or through inter-institutional loan. They will agree to let other participating institutions know of their intent to deselect last copy material in advance of actual disposal. They will agree to give other institutions the opportunity to request transfer of these resources to their holdings for ongoing care and access; accommodating transfer to another institution will not necessarily constitute paying for its transfer, it will involve coordinating with the requesting institution the identification of holdings that will be transferred, what packing and shipping arrangements will be made, including date, time, locations, insurance, payment, etc.

These principles are to ensure that participating institutions know from the start the commitments they are making, and that all participants agree to them. While these principles addressed the high-level responsibilities relevant to a successful working of the Last Copies Initiative, they were in turn based on characteristics or underpinnings aimed at guiding the orientation and the decision making in such an initiative. These characteristics, or attributes, are:

- Visionary: circumstances are such that bold action is necessary from the Canadian library community.

- Comprehensive: the Initiative's intent is to include management of any library holding. Currently print, monographs, monographic series, and serials, are included. Audio visual material will belong to a later phase. Digital on-line material is not part of the current scope.

- Inclusive: while interest may be greater among some segments of the Canadian library community, it is intended for the entire community to participate. 
- Sustainable: either through local or regional efforts, the initiative must be economically viable over a long period of time.

- Collaborative: success is dependent on the collaboration of all interested parties.

- Distributed: building on the strengths and expertise of the partners, a coordinated and distributed approach is taken, as opposed to a centralized or top down approach.

- Voluntary: participation is not imposed or compulsory, institutions decide to become involved.

- Accountable: while participation is voluntary, once this decision has been made, there is a commitment to account for an institution's responsibilities and actions.

- Transparent: decisions and actions are made known through robust data outlining access conditions and preservation activities.

- Standards based: while there is acknowledgment that commonly accepted metadata standards (e.g., Marc format) will be used, further discussions will be needed, especially around preservation standards and metadata.

- Trust based: linked to the voluntary approach, and based on existing relationships, trust among participants will be a key success factor.

In practical terms participating to this Initiative will help libraries in identifying the holdings they have in common across the country; in determining the number of copies to be kept in Canada and in which geographical areas, based on users' demand; in identifying the last copies held in the country; in removing holdings that are infrequently used by users and/or with content available in digital formats; in registering last copies in a consistent way in systems across Canada; in ensuring compatibility of metadata for analog and digital holdings; and in reallocating space for other purposes, if so desired by the participants.

These 6 principles were endorsed by the Management Board of LAC in May 2013, as it agreed to manage its own collection accordingly. LAC also agreed to coordinate this national initiative and to take the lead in the development of its policies.

In other words, the framework around the Initiative had been developed. However, questions around its actual implementation still remained. As a first step a Canadian Overlap Study was initiated with the purpose of providing a national picture of library holdings, thus providing a wider and more comprehensive view than the regional initiatives mentioned above. OCUL, COPPUL, the University of Toronto, McGill University, and LAC agreed to con- duct this study that was to analyze in its first phase the holdings of CARL research libraries, as well as those of some large public libraries. These institutions represent about $85 \%$ of Canadian holdings, and this study would provide a sound overview of the situation. A second phase of the study was to include smaller libraries. This phase would likely bring a more varied picture: while one can anticipate commonly held titles, it is also likely to highlight rarer, local Canadiana material. In the latter category last copies, if not kept by the current holder, would be of great interest to LAC, as these titles correspond to its mandate, and may be missing from its current holdings.

This study requires solid data sets representing titles and physical items per library and/or per peer group of libraries, and identifying duplicate bibliographic records. This information was to be extracted from the official National Union Catalogue hosted by LAC on its Amicus database from OCLC, a service provider used by many Canadian libraries, as well as from regional union catalogues. This analysis would also result in a better understanding of the relationships between libraries' specific holdings and the overall picture, i.e. are multiple copies held by a small number of institutions, or by many? Are these institutions in the same geographical area? A draft plan for this study was drafted in April 2015. The lack of analytical functionality on Amicus to provide the type of data necessary proved more than problematic, it contributed largely to a hiatus in the project. In 2014 LAC also announced its intent to replace Amicus by OCLC which can provide better functionality through its print share services which is an option that can be pursued by LAC for itself, and on behalf of other libraries. Under these circumstances, it made sense to wait.

While the project is on hold, LAC has improved its infrastructure capacity by opening a new Collection Storage Facility in 2014, and is planning an additional preservation facility likely to be open in 2020 . This contributes greatly to LAC's capacity to hold last copies, especially for rarer Canadiana material. In addition, LAC has created and maintained a Web presence for this initiative. ${ }^{5}$

\section{Lessons learned and next steps}

The development of principles and characteristics has proven to be the right approach in the Canadian context: LAC and its predecessor, the National Library of Canada, are

5 http://www.bac-lac.gc.ca/eng/services/last-copies/Pages/last-cop ies-portal.aspx. 
fairly recent institutions, its collecting mandate is quite specific to Canadiana, and its role takes place in an environment where many large libraries, both academic and public, have broader collecting mandate and large holdings. The development of these principles has created a framework to which any institution can adhere on a voluntary basis. This distributed or federated approach will also ensure engagement and commitment from all participants to pursue of the objectives of the Initiative. Simply said, a top-down approach with rigid guidelines would have been a nonstarter.

The importance of appropriate and easy to use tools/ systems has proven paramount. The Initiative has been delayed because of their absence. This consideration is directly linked to the sustainability of the project, participating institutions are unlikely to afford heavy investments on this initiative, and the use of efficient tools will be the key to its implementation success.

Notwithstanding the positive of the approach and framework, and the negative of the systems question, the full implementation is likely to raise issues that are lying below the surface of the Principles. The issue of metadata, and more importantly its compatibility between libraries, will be the key as a consistent use of metadata will enable communication of holdings, and last copies between participants. Ease of communication will also depend on efficient workflows that will enable the identification of last copies and their transfer to other locations in the network. Metadata and workflows are not questions that will automatically be answered by better systems, they are critical components of a successful systems implementation, and must be integrated as part of the systems solution. The question of sustainability has been raised earlier but cannot be underlined enough: the Last Copy Initiative comes from a deep sense of commitment from the participants towards published heritage, its preservation, and access. It is an initiative with a long-life cycle, and while resources may be required more intensively at the beginning of its implementation, an on-going commitment will be necessary, and in turn this commitment is more likely to be achieved through ease of use and efficiency in its operations.

Clarity and communication of what constitutes reasonable access and preservation environment are also issues likely to be raised. The question of how many copies to preserve will be easier to address following the Overlap Study. It had been raised from the beginning in the 2011 CARL report, and many factors are likely to come into play: the subjects of the material and corresponding access needs, the geographic distribution of the copies. It is unlikely that a "one size fits all" solution will apply. This will lead to the question of the trigger point at which the last copy mechanism will be applied. It is possible that a statistical analysis may be beneficial, e.g., is there a risk ceiling for the number of copies above which the possibility of losing all copies is so insignificant that no immediate action is required?

The recent contract signing (March 2017) between LAC and OCLC should eventually lead to better technical solutions to address these questions. Interest in the community, especially among research libraries, has picked up again, and while because of the hiatus, many "players" have changed, the wide and clear benefits of this initiative and its relevance remain, now and for the future. A symposium on last copies is likely to be hosted by LAC in the fall of 2017. This takes us back to the importance of the 6 principles, as they will govern the consultations and consensus building that will be at the core of a fruitful implementation of the Last Copy Initiative, and of its continued success.

Finally, I wish to thank Robert McIntosh and Sylvain Bélanger, both former Director General of the Preservation Branch at LAC, for their role at various stages of this initiative, and the various representatives of associations and institutions mentioned above that have contributed so richly. Including these, 27 associations, organizations and institutions have stated an interest in participating. They are namely: The Association of Parliamentary Libraries of Canada, The British Columbia Electronic Library Network, Bibliothèque et Archives nationales du Québec, Canadian Association of Research Libraries, Canadian Library Association, Canadian Urban Libraries Council, Concordia University, Conférence des Recteurs et Principaux des Universités du Québec, Council of Atlantic University Libraries, Council of Prairie and Pacific University Libraries, Dalhousie University, Greater Victoria Public Library, Library and Archives Canada, Library of Parliament, McGill University, Nipissing University, Novanet, ${ }^{6}$ Ontario Council of University Libraries, Ontario Legislative Library, Simon Fraser University Library, Toronto Public Library, University of Alberta Library, University of British Columbia, University of Manitoba Library, University of New-Brunswick, University of Toronto, and Vancouver Public Library.

6 Note: Novaner is a library consortium based in the province of Nova Scotia. 


\section{References}

Canadian Association of Research Libraries (2011): The Permanent Conservation of Print Collections in Canada: a Model for Consideration by the CARL Scholarly Communication Committee. Available at http://www.carl-abrc.ca/doc/pcpc_recommendations-e. pdf.

Stambaugh, Emily (2011): Shared Print Archiving among the Council of Prairie and Pacific University Libraries. Final report.

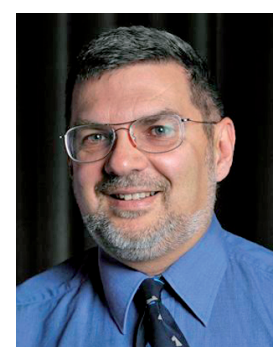

Pierre Gamache

261 Lincoln Heights Rd.

CA-Ottawa, ON K2B 5L7

Canada

pierre.gamache102@gmail.com 